the book will be of most use to those who wish to dip into the relationship between law, ethics and medicine without being overwhelmed by detail. It should not be seen as taking such a person too far as it does not provide a comprehensive study and is weighted towards the state of New York. Nevertheless, it will provide much food for thought.

JONATHAN MONTGOMERY Faculty of Law University of Southampton, England

\section{Ethical Dilemmas In Health Promotion}

Edited by Spyros Doxiadis, 234 pages, Chichester, £38.00, John Wiley and Sons, 1987

This is a book to be welcomed since it puts philosophical issues surrounding the area of health promotion firmly into the arena for discussion, alongside the more traditional areas of practice, economics, training and so on. Up to now, it has been hard for students and practitioners in the field of health to have easy access to the kinds of arguments and processes which ought to be part of their everyday questioning about their professional practice, and this book goes some way towards identifying some of the main issues and the ways in which we might begin to think about them.

Having said that, I want to qualify my comments. I believe that this book will prove to be extremely useful as an initial publication in the debate but, because it is early days, there seems to be no overall framework within which the various contributions can be placed. The general bias in the book, whether through the professional training or present perspectives of the authors is towards medicine, with a model of health which is about illness, its prevention or cure, and about a normative model of practice which postulates, overtly or covertly, an expertise whose basis - that medical knowledge equals health - is never fully examined. There are some assumptions and assertions which merit more rigorous critical treatment in a book which is likely to carry a great deal of weight. Rayner, for example, asserts that health education is about the giving of information and messages which may be positive or negative (my emphasis), implying a power relationship which many health educators would want to question; whilst many of the other authors seem to use the terms 'health promotion', 'health education', 'medicine' and 'prevention' as if the concepts to which these labels are attached were interchangeable, with no difference in meaning. Conceptual woolliness of this kind is a disappointment from such an impressive array of authors.

But these criticisms are, I think, merely indicative of the 'state of the art' and further debate, likely to be stimulated by this publication, will challenge and refine the arguments. There is much here which is thoughtprovoking, and likely to generate feelings of dissonance in the reader never a bad thing for those of us who claim to be working in other people's interest! In general, the style of writing is clear and easy to read - crucially important if health professionals new to philosophy are to be encouraged to 'read on'. Above all, the book embraces a range of issues which have relevance at micro and macro levels, enabling us to engage in our own problems as well as considering a world view. It thus challenges us to focus on our own work yet forces us to acknowledge our wider responsibilities. Definitely 'essential reading' for any postgraduate course for health professionals of all kinds; I just hope that the readership won't be confined to such groups, but that all those interested in improving health will read it.

GILL WILLIAMS Lecturer in Health Education, recently retired, King's College University of London

\section{Child Psychiatry and the Law}

Edited by Dora Black, Stephen

Wolkind and Jean Harris Hendriks, 178 pages, London, $£ 10.00$, Gaskell/ Royal College of Psychiatrists, 1989

The Royal College of Psychiatrists has continued its excellent series of practical and important books on topics in clinical psychiatric practice, with this, the first book in its series oriented towards child psychiatrists. It is a pity that this book should be published when the legal information in it is about to be rendered obsolete by the implementation of the Children Act 1989. In spite of this, there is a fund of information clearly laid out and adequately indexed to make possession of this publication essential to British child psychiatrists and paediatricians, and of use to others concerned in the care and rights of children.

In recent years, child psychiatrists have frequently been called on, both by the courts and local authorities, to give an expert opinion, from knowledge of clinical and research experience, about the best interests of children with whom they have been concerned. The anxiety created in the public domain by the exposure of the extent to which children are abused, both by their parents and carers, the relative neglect of their interests, and a change in the emphasis of the law from the preoccupation with the child as the property of the parent, to a person with individual rights of its own, has led to a situation where the skills of the child psychiatrist to deal with the resulting decision and anxiety, is increasingly called on.

By discussing the tasks of the child psychiatrist exposed to the demands of the legal professional discipline, and the practical aspects of the child psychiatrist's appearance in the legal system, this book provides a means whereby many of the pitfalls can be avoided. The child psychiatrist is made aware of the need to defend opinions and statements, which must enrich general clinical experience and practice.

Section two of the book, by giving examples of actual court reports, indicates the different styles of report which might be available to a practitioner, while the check-lists at the end of each chapter provide a most useful reminder when writing reports, or considering their presentation. The chapter on fees gives pointers for those whose knowledge of the private sector is very limited, but omits to mention that the BMA issues guidelines as to fees payable for Section 2 work and court appearances.

The chapters on confidentiality are concise and define the responsibility the child psychiatrist has to the child, rather than to the parents or to the agency which solicits the report. Most reports about children are necessarily reports about the family in which the care of the child has broken down, which has resulted in the child's appearance in the legal system. There is inadequate discussion of the rights of the parents in such a system.

The area which causes greatest anxiety, namely appearance in court, when an expert witness is subjected to cross-examination, is addressed. It might have been helpful if: i) further discussion of the experience of evidence-giving had been included, and 